\title{
Dynamics of Iron in Rhizosphere
}

\author{
Lokesh Patil $^{1 *}$, G.S. Yogesh ${ }^{2}$, N. Hamsa ${ }^{1}$ and H.M. Honnappa ${ }^{1}$ \\ ${ }^{1}$ Department of Soil Science and Agricultural Chemistry, UAS GKVK, Bengaluru, 560065, India \\ ${ }^{2}$ Subject Matter Specialist (Soil Science) Krishi Vigyan Kendra, Haradanahally, \\ Chamarajnagar, 571 313, India \\ *Corresponding author
}

\begin{tabular}{|c|c|}
\hline & A B S T R A C T \\
\hline & \multirow{6}{*}{$\begin{array}{l}\text { Iron (Fe) in the soil is present mostly in the form of insoluble Fe (III) oxides and } \\
\text { hydroxides (e.g. haematite, goethite, ferrihydrite). The total iron in soil is much higher } \\
\text { than most crops require. Nevertheless, the concentration of free Fe (III) in most } \\
\text { agricultural soils is far below that required for optimal plant growth, which is between } 10^{-9} \\
\text { and } 10^{-4} \mathrm{M} \text { Fe (III) in the soil solution (Lindsay and Schwab, 1982). Generally, chelation } \\
\text { of Fe (III) is the most successful mechanism by which plants roots can acquire Fe. } \\
\text { Production of chelating compounds by microorganisms increases Fe solubility in the } \\
\text { rhizosphere and hence increases plant Fe acquisition. Bacterial and fungal siderophores } \\
\text { and other chelating metabolites are assumed to serve as major sources of plant-available Fe } \\
\text { in the rhizosphere. Moreover, from the earlier literature it is well known that microbial } \\
\text { chelates produced in the rhizosphere mobilize Fe (III) from insoluble Fe sources. In } \\
\text { cultivated soil iron is oxidized to form ferric oxide and oxy hydroxides results in low } \\
\text { availability of iron for living organisms. To face the demand of Fe (III) in the rhizosphere } \\
\text { leads to strong competition for this nutrient among living organisms, plants and } \\
\text { microorganisms have developed active strategies of iron uptake. Efficient siderophores of } \\
\text { microbial populations from the rhizosphere do not compete with the plant harboring them, } \\
\text { and even seems to contribute to the plant iron nutrition. The complex interaction between } \\
\text { soil chemical properties, plants, and microbes affects the iron dynamics in the rhizosphere, } \\
\text { which in turn impact the plant health and nutrition. }\end{array}$} \\
\hline Keywords & \\
\hline $\begin{array}{l}\text { Rhizosphere, Iron } \\
\text { dynamics, } \\
\text { Siderophores, } \\
\text { Chelating ligands. }\end{array}$ & \\
\hline Article Info & \\
\hline $\begin{array}{l}\text { Accepted: } \\
\text { 26 September } 2017 \\
\text { Available Online: } \\
10 \text { October } 2017\end{array}$ & \\
\hline & \\
\hline
\end{tabular}

\section{Introduction}

Iron is essential for major metabolic processes in most organisms such as reduction of ribonucleotides and molecular nitrogen and the energy-yielding electron transfer reactions of respiration and photosynthesis (Guerinot and Ying, 1994). In the rhizosphere, this concentration is even lower due to the iron uptake by both roots and microbes, and the concentrations of Fe(III) species are generally far below those required for optimal growth of microbes and plants.
The combined low concentration of Fe (III) in soil solution (low supply) together with the requirements of aerobic organisms (plants and microorganisms) creates high demand lead to a considerable level of competition for $\mathrm{Fe}$ (III) in the rhizosphere. To acquire this essential element in spite of its low availability, plants and microbes have evolved active strategies of uptake which are based on a range of chemical processes (Loper and Buyer, 1991). 
Iron dynamics in the rhizosphere are under the control of the combined effects of soil properties, uptake and activities of plants and microorganisms and interactions between them. In this review, the status of iron in soils and rhizospheres will be examined.

\section{Iron status in soils}

Iron is the $4^{\text {th }}$ most abundant element in the earth's crust after O, Si and $\mathrm{Al}$ (Ma, 2005). And it ranges in soil from 1- $5 \%$ total $\mathrm{Fe}$ in plough layer and in plants more than $50 \mathrm{ppm}$. It occurs in two oxidation states as Ferric (III), Ferrous (II). Availability of Fe is more in acidic $\mathrm{pH}$ predominantly included in the crystal lattice of a range of primary and secondary ferromagnesium silicates and in high $\mathrm{pH}$ Fe (III) precipitate as hydroxides, oxy hydroxides and oxides so concentration of $\mathrm{Fe}^{3+}$ in the soil solution is extremely low.

Chemical reaction of iron (Inglett et al., 2006)

\section{Aerobic condition}

Oxidation $-\mathrm{Fe}^{2+}$ to $\mathrm{Fe}^{3+}$.

$\mathrm{Fe}(\mathrm{OH})_{3} \leftrightarrows \mathrm{Fe}^{3}+3 \mathrm{OH}$

$\mathrm{FeOOH}+3 \mathrm{H}^{+} \leftrightarrows \mathrm{Fe}^{3}+2 \mathrm{H}_{2} \mathrm{O}$

Soluble - Less soluble

\section{Anaerobic condition}

Reduction- $\mathrm{Fe}^{3+}$ to $\mathrm{Fe}^{2+}$.

$\mathrm{Fe}(\mathrm{OH})_{3} \leftrightarrows \mathrm{Fe}^{2+}+\mathrm{H}_{2} \mathrm{O}$

More soluble.

\section{Role of iron}

Iron plays critical role in metabolic processes such as DNA synthesis, respiration and photosynthesis. It is necessary for the synthesis and maintenance of Chlorophyll. It is a structural component of the molecules like Cytochromes, Peroxidase, Haematins and
Catalase etc. It activates a number of enzymes like Pxygenase, Dioxygenases, Ferredoxin hydrogenase, Glutamate synthase (Rout and Sahoo, 2015).

\section{Iron deficiency symptoms}

Symptoms of iron deficiency appear on the youngest, newest leaves. The area between the leaf veins becomes pale yellow or white (Eskandar, 2011).

Under severe deficiency condition tissues show necrotic symptom Necrosis spreads from tip and margin into interveinal zones. In barley, maize and jowar leaves, reddish spots may be formed.

\section{Rhizosphere soil}

Hiltner (1904) proposed the name rhizosphere for designing the volume of soil surrounding roots in which microorganisms are influenced by those roots. Since then, further studies have shown that living roots modify the biological, physical, and chemical properties of the surrounding soil. The Rhizoplane is the medial zone directly adjacent to the root including the root epidermis and mucilage.

Iron status in soils and rhizospheres (Robin et al., 2008)

Iron in primary and secondary minerals

Ex: Biotite, Hornblende, Olivine, Augite.

Soluble iron

Ex: Hydrous ferric oxide, Goethite, Hematite

Iron bound to organic matter

More than $95 \%$ of $\mathrm{Fe}$ in soil solution Chelated (organic ligands) 


\section{Microbial siderophores}

Siderophores (Greek: "iron carrier") are small, high affinity iron chelating compounds secreted by microorganisms such as bacteria, fungi. The production of siderophores is an efficient strategy of bacteria, fungi and graminaceous plants to overcome a lack of iron. The stability of the siderophore iron complex is an important factor for the efficiency of the siderophores (Wittenwiler, 2007).

\section{Example}

Short-Term Effects of Rhizosphere Microorganisms on Fe Uptake from Microbial Siderophores by Maize and Oat

When FePSB was supplied to maize plants under varied microbial population density in the nutrient solution, dramatic differences in "Fe uptake rate i.e concentrations in roots and shoot were observed. These differences did not correspond with Fe translocation rate i.e concentration in shoots. Under Fe deficiency, the 55Fe uptake rates from FePSB increased with increased microbial population density, but the translocation rate remained at a similarly low level as in the $\mathrm{Fe}$ sufficient plants.

The increase in $\mathrm{Fe}$ concentration was more distinct by inoculation with $P$. putida, which is the producer of PSB and utilizes it via a specific membrane-bound receptor. When ferrated phytosiderophores (FeHMA) were used as the Fe source, the uptake and translocation rates of "Fe were higher than those with FeEDDHA or FePSB. Similar results were obtained for oat plants. The uptake and translocation rates of "Fe from FeHMA were higher than the bacterial siderophore FeFOB. The uptake and translocation rates of "Fe from FeHMA were higher than the bacterial siderophore FeFOB.
A low rate of translocation associated with high root accumulation is a strong indication for involvement of rhizosphere microorganisms.

Population of ferric iron-reducing bacteria the rhizoplane of a wetland rice during the growth cycle in a micro plot experiment. Ironreducing bacteria greatly increase in number at the beginning of the reproductive growth phase of rice. In the case of iron-reducing bacteria, this increase can be ascribed to an enhanced exudation of carbohydrates and other metabolites during heading of rice panicles, finally leading to severe iron toxicity ((Prade, 19871).

\section{Plant root exudates}

Photosynthates are released from plant roots to soil through a process called rhizodeposition. Ex: Lysates, mucilage, dead cell material and ethylene. Increasing root exudates in soil enhances the soil fertility level as well as microbial biomass. These soil microbes play vital role in nutrient transformation reactions in soil and nutrient uptake by crop plants (Dotaniya et al., 2013).

This increase in $\mathrm{Fe}$ content was about two times higher in the $\mathrm{Fe}$ sufficient $(+\mathrm{Fe}$ pretreated) plants compared with the $\mathrm{Fe}$ deficient (-Fe pretreated) plants. The calculated uptake rate for $\mathrm{Fe}$ during the $4 \mathrm{~d}$ treatment was about 2.5 times higher in the $\mathrm{Fe}$ deficient seedlings (Awad et al., 1994) this enhancement in Fe solubility is mainly due to phytosiderophores released by the roots of wheat seedlings.

It has been shown that in chlorotic graminaceous plants the main component of the low-molecular-weight root exudates (more than $80 \%$ ) are phytosiderophores which has been characterized as nonproteinogenous amino acids. 


\section{Phytosiderophores}

Organic substance produced by the plants under Fe deficient condition, which can form organic complexs with $\mathrm{Fe}^{3+}$ and increases the movement of $\mathrm{Fe}$ in soils (Mori and Nishizawa, 1987).

Phytosiderophors are secreted from plant root, and it is a lifesaving mechanism in plants. It enhances the plant nutrient uptake and improves the soil health. Iron availability is low in most aerobic soil, and microorganisms and plants release low molecular-weight compounds (chelators) which increase $\mathrm{Fe}$ availability.

It spe-cially enhances the uptake of Fe and $\mathrm{Zn}$ in lower concentration (Dotaniya et al., 2013). In the rhizosphere the concentration of phytosiderophores may be in the range of 1 $\mathrm{mM}$ and even higher, suggesting that they also play an important role in Fe transport to the root surface.

\section{Characteristics}

PS are produced $3 \mathrm{hr}$ after onset of the light period

Highly affinity for $\mathrm{Fe}^{3+}$ and removes from minerals

Highly soluble Fe chelate

Regulates the mechanism for the biosynthesis under Fe deficient condition

Usually, the amounts of ferrous iron in the soil solution of flooded soils are significantly higher in planted than in unplanted soil (Fig. 1). This result shows that, despite the aeration mechanism of the roots, iron-reduction processes in the bulk soil are stimulated by the physiological activity and by the growth of rice roots (Jacq et al., 2000).
Fe movement in the growth medium is also influenced by the chelating ligand species

Chelating ligands have been used in agriculture as an additive in micronutrient fertilizers in order to increase $\mathrm{Fe}$ bioavailability (Alvarez-Fernandez et al., 2005). Ferric ions and their complexes have low solubility in aquatic systems, but they are extensively buffered by chelation (Morel and Hering, 1993), which increases their dissolved concentration. The dissolved concentration of Fe determines its rate of uptake by organisms.

The growth of radish sprouts was correlated with the Fe concentration in the plant tissues. The heights of the radish sprouts increased with higher tissue $\mathrm{Fe}$ concentrations (Fig. 2). The $\mathrm{Fe}$ concentration in the tissues of the radish sprouts was dependent on the chelating ligands, since the $\mathrm{Fe}$ was not readily bioavailable under experimental conditions (at $\mathrm{pH} 10$ ) before the addition of ligands. Compared to the control, the Fe concentration in the sprouts increased with the addition of chelating ligands. The $\mathrm{Fe}$ uptake in radish sprouts was increased by $79 \%$ with the addition of HIDS to the growth medium (Hasegawa et al., 2011). Synthetic Fe (III)chelates, such as EDTA and EDDS, are the most common and effective ligands used to increase $\mathrm{Fe}$ bioavailability. HIDS is a new chelating ligand with high biodegradability and a high stability constant with $\mathrm{Fe}^{3+}$ (Hasegawa, 2011).

\section{Iron solubilization in the rhizosphere}

Acidification through proton extrusion and organic acid secretion (and possibly respiration)

Chelation through secretion of complexing molecules with variable affinity for iron (phytosiderophores, siderophores, phenolics, and carboxylic acids), and reduction through 
secretion of compounds characterized by reducing properties or through the expression of a membrane-bound reductase activity
(Darrah, 1993; Hinsinger et al., 2003; Siebner-Freibach et al., 2003).

Fig.1 Fe (I1) - concentrations (ppm) in the rhizospheric soil solution of differently fertilized wetland rice (IR-8 cultivar) in comparison with an unplanted soil during a field experiment in Senegal

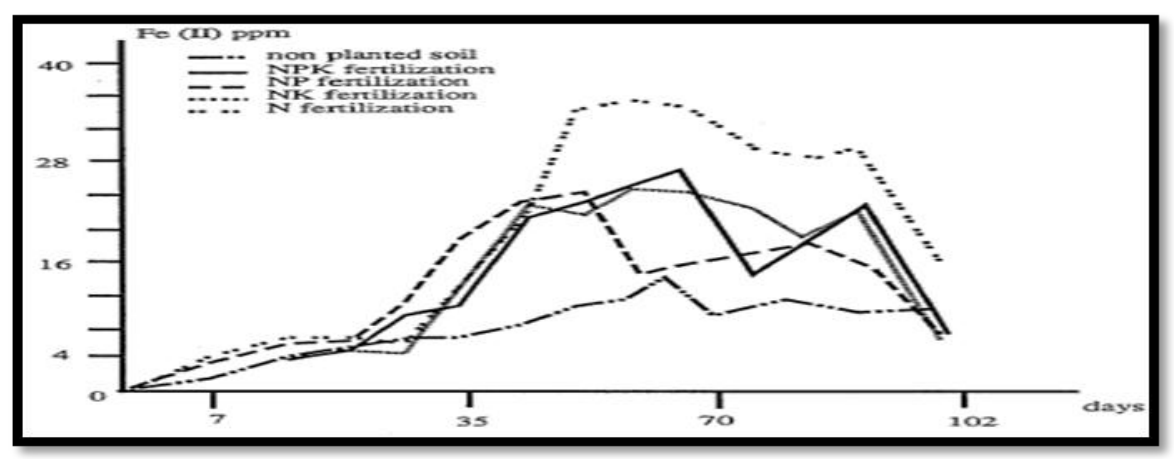

Fig.2 Iron uptake and growth of radish sprouts in medium with Fe-complexing chelators

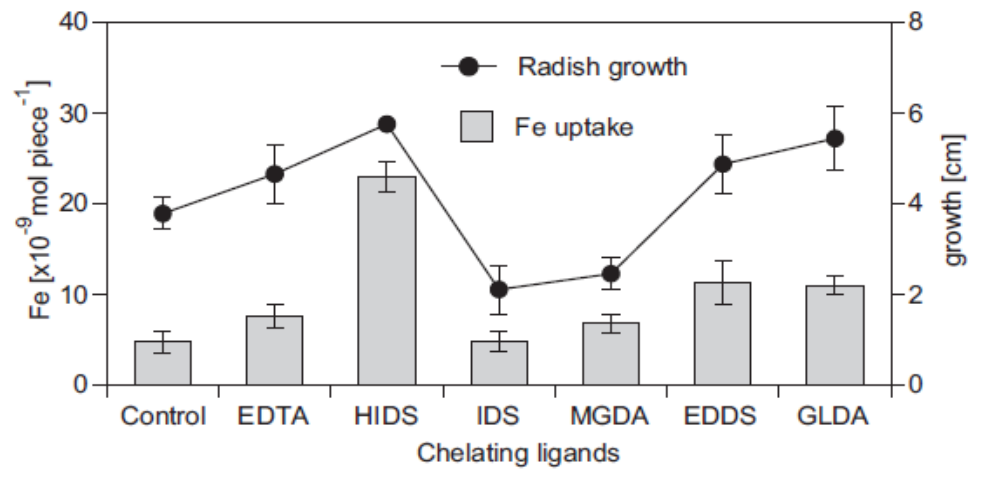

Fig.3 Schematic representations of mechanisms affecting iron availability in the rhizosphere.

Plants and microorganisms may increase iron availability

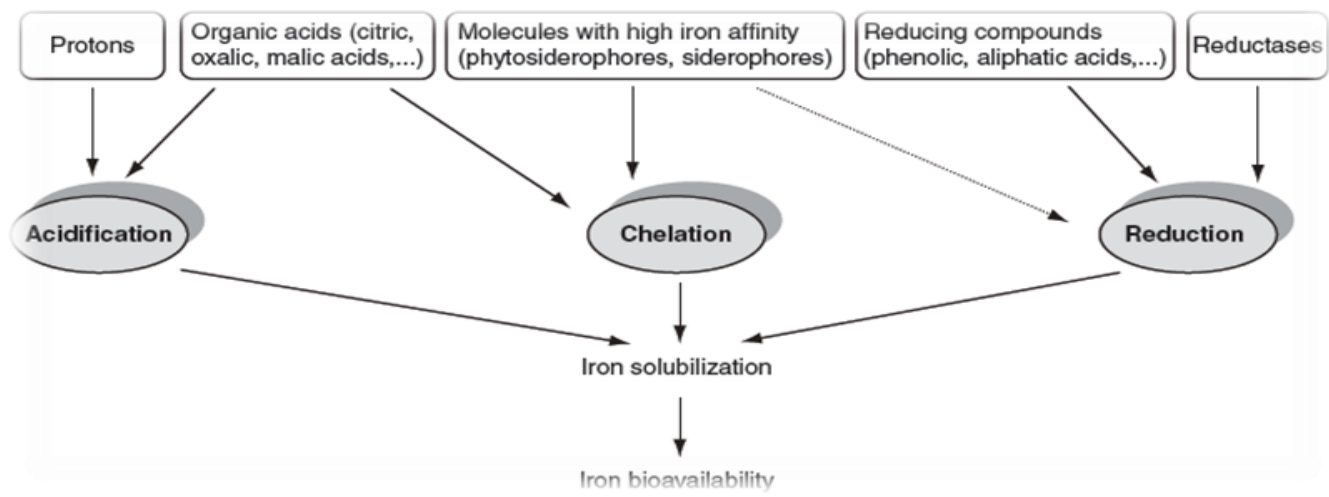


Fig.4 Schematic representations of iron-mediated interactions between plants and microbes promoting plant health and iron nutrition

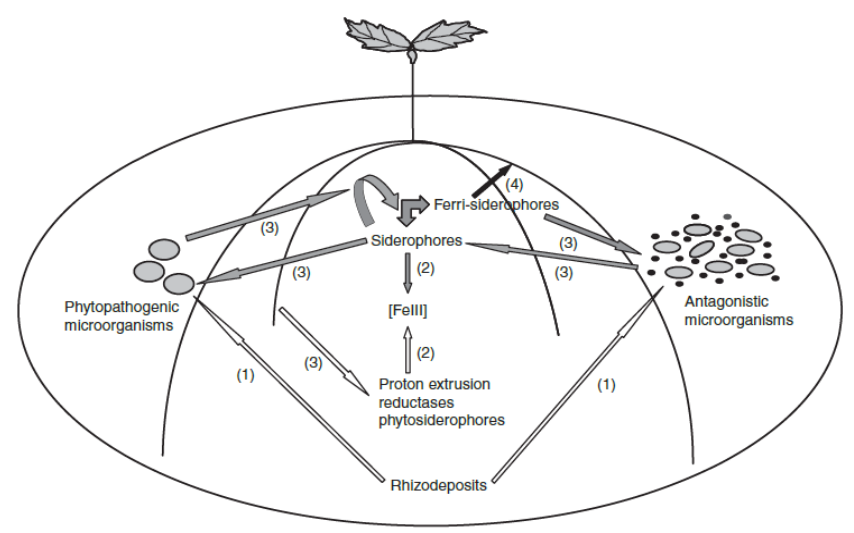

Fe deficiency differs according to the strategy of iron uptake

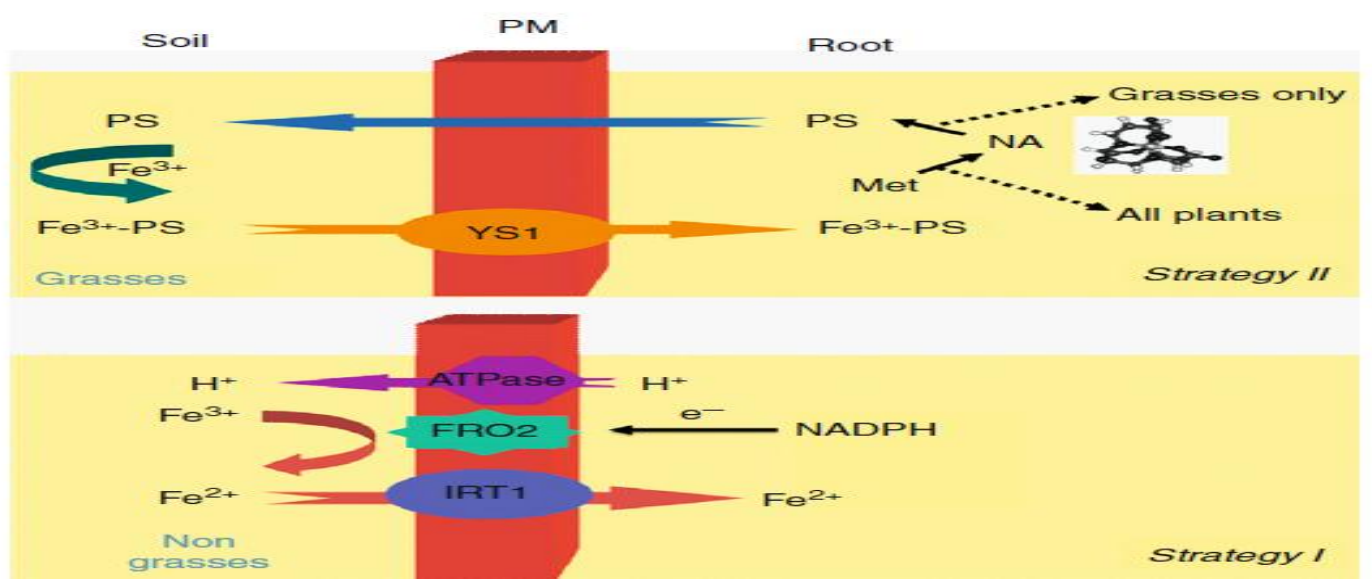

Table.1 55Fe Uptake and Translocation Rates in Fe-Sufficient (+Fe) and Fe-Deficient (-Fe) Maize Plants Supplied with 55FePSB, 55FeEDDHA, and 55FeHMA under Various Densities of Microorganism Population Eli et al., 1992

\begin{tabular}{|c|c|c|c|c|c|}
\hline \multirow{2}{*}{ Treatment } & \multicolumn{2}{|c|}{${ }^{55} \mathrm{Fe}$ Uptake Rate } & \multicolumn{2}{|c|}{${ }^{55} \mathrm{Fe}$ Translocation Rate } & \multirow{2}{*}{ Microorganisms } \\
\hline & $+\mathrm{Fe}$ & $-\mathrm{Fe}$ & $+\mathrm{Fe}$ & $-\mathrm{Fe}$ & \\
\hline & \multicolumn{4}{|c|}{$\mathrm{nmol} \cdot \mathrm{g}^{-1} \cdot 10 \mathrm{~h}^{-1}$} & CFU $\mathrm{mL}^{-1}$ \\
\hline \multicolumn{6}{|l|}{ FePSB } \\
\hline Uninoculated & $17.6 \mathrm{~cd}$ & $37.2 \mathrm{~d}$ & $3.3 \mathrm{a}$ & $1.9 \mathrm{C}$ & $1.6 \cdot 10^{3}$ \\
\hline Axenic & - & $24.2 \mathrm{e}$ & - & $8.8 \mathrm{a}$ & $<1$ \\
\hline Soil bacteria & $56.4 \mathrm{~b}$ & $115.6 \mathrm{~b}$ & $1.8 \mathrm{~b}$ & $0.8 \mathrm{~d}$ & $7.0 \cdot 10^{9}$ \\
\hline Pseudomonas & $121.5 \mathrm{a}$ & $1125.7 \mathrm{a}$ & $1.7 \mathrm{~b}$ & $0.8 \mathrm{~d}$ & $2.0 \cdot 10^{10}$ \\
\hline Antibiotics & $23.6 \mathrm{c}$ & $55.8 \mathrm{c}$ & $4.1 \mathrm{a}$ & $5.6 \mathrm{~b}$ & $5.0 \cdot 10^{1}$ \\
\hline \multicolumn{6}{|l|}{ FeEDDHA } \\
\hline Uninoculated & $15.1 \mathrm{~b}$ & $25.2 \mathrm{c}$ & $4.4 \mathrm{c}$ & $7.1 \mathrm{a}$ & $1.8 \cdot 10^{3}$ \\
\hline Soil bacteria & $27.4 \mathrm{a}$ & $37.3 \mathrm{~b}$ & $10.4 \mathrm{a}$ & $5.0 \mathrm{ab}$ & $3.0 \cdot 10^{10}$ \\
\hline Pseudomonas & $25.5 \mathrm{a}$ & $79.1 \mathrm{a}$ & $10.1 \mathrm{a}$ & $2.7 \mathrm{bc}$ & $5.0 \cdot 10^{10}$ \\
\hline Antibiotic & $14.0 \mathrm{~b}$ & $10.8 \mathrm{~d}$ & $5.2 \mathrm{bc}$ & $3.5 \mathrm{~b}$ & $2.0 \cdot 10^{2}$ \\
\hline \multicolumn{6}{|l|}{$\mathrm{FeHMA}$} \\
\hline Uninoculated & $2578 \mathrm{~b}$ & $3465 \mathrm{~b}$ & $1572 b$ & $2217 b$ & $1.8 \cdot 10^{3}$ \\
\hline Soil bacteria & $1231 \mathrm{c}$ & $1578 \mathrm{c}$ & $743 \mathrm{c}$ & $707 c$ & $9.0 \cdot 10^{9}$ \\
\hline Antibiotic & $4758 \mathrm{a}$ & 5057 a & 3257 a & $3822 \mathrm{a}$ & $6.0 \cdot 10^{1}$ \\
\hline
\end{tabular}


Time-course of changes in the available iron concentration in the rhizosphere of peanuts induced by intercropping

The different cropping systems affected the available $\mathrm{Fe}$ concentration in the rhizosphere of peanut and maize. Generally, the available $\mathrm{Fe}$ concentration was increased in the rhizosphere in intercropped peanuts at all growth stages (34-76 days). Indicating that intercropping could consistently provide more available $\mathrm{Fe}$ to peanut than monocropping over a longer period of time. The available Fe showed no significant change with time under monocropping.

Intercropping significantly improved the available $\mathrm{Fe}$ concentration in peanut rhizosphere during the reproductive stage, at 60-76 days. In particular, at 60 days, where there was obvious Fe-deficiency chlorosis in the monocropped peanuts, the intercropped system could maximize DTPA-Fe concentrations in the rhizosphere of peanut plants (Guo et al., 2014).

Fe deficiency differs according to the strategy of iron uptake

\section{Active strategies (Römheld and Marschner 1986)}

In soil low concentration of $\mathrm{Fe}$ (III) and Requirement of aerobic organisms creates high demand for $\mathrm{Fe}$ so competition for $\mathrm{Fe}$ (III) in the rhizosphere than Plants and microbes have evolved active strategies

Acidification of the soil solution based on the excretion of protons or organic acids,

Chelation of Fe (III) by plant and microbial ligands showing a high affinity for $\mathrm{Fe}^{3+}$

Reduction of $\mathrm{Fe}^{3+}$ to $\mathrm{Fe}^{2+}$ mostly by plant reductases and reducing compounds.

\section{Strategy I}

Crop species (Peanut, Cotton, Cucumber, Pea, Carnation).

\section{Strategy II}

Graminacious plant species (Barley, Maize, Sorghum, Oat) are more efficient to overcome the deficiency of iron

Iron-mediated interactions between plants and microbes promoting plant health and iron nutrition (Robin et al., 2008)

Plants release a variety of organic and inorganic substances (rhizodeposits) which exert a direct influence on soil borne microorganisms including antagonistic and phytopathogens populations. The concentration of $\mathrm{Fe}$ (III) in solution is decreased in the rhizosphere due to its uptake by roots and microbes.

Active iron acquisition strategies are activated; antagonistic microorganisms produce siderophores showing a higher affinity for iron than those of phytopathogens leading to their suppression (microbial antagonism).

Microbial siderophores may also elicitate defense reactions in the host plant and promote plant iron nutrition. Altogether, these different actions promote plant health and iron nutrition.

Synthetic Fe (III)-chelates, such as EDTA and EDDS, are the most common and effective ligands used to increase $\mathrm{Fe}$ bioavailability. The performance of HIDS with respect to $\mathrm{Fe}$ movement in growth medium and radish growth was higher than that of other chelating ligands tested. Thus, HIDS would be a good alternative to EDTA and other poorly biodegradable chelating ligands. 


\section{References}

Alvarez, F. A., Garcia, M. S. and Lucena, J. J. 2005. Evaluation of synthetic iron(III)chelates $\left(\mathrm{EDDHA} / \mathrm{Fe}^{3+}, \mathrm{EDDHMA} / \mathrm{Fe}^{3+}\right.$ and the novel EDDHSA/ $\mathrm{Fe}^{3+}$ ) to correct iron chlorosis. Eur. J. Agron. 22: 119130.

Awad, F., Romheld, V. and Marschner, H. 1994. Effect of root exudates on mobilization in the rhizosphere and uptake of iron by wheat plants. Pl. Soil. 165(2): 213-218.

Darrah, P. R. 1993. The rhizosphere and plant nutrition - a quantitative approach. $\mathrm{Pl}$. Soil. 156: 1-20.

Dotaniya, M. L., Dasharath Prasad, H. M., Meena, D. K., Jajoria, G. P., Narolia, K. K., Pingoliya, O. P. M., Kuldeep Kumar, B. P. M., Asha Ram, H., Sreenivasa Chari, M. and Suresh Pal. 2013. Review Influence of phytosiderophore on iron and zinc uptake and rhizospheric microbial activity. African J. Microbiol. Res. 7 (51): 5781-5788.

Eli Bar-Ness, Yitzhak, H., Yona, C., Volker, R. and Horst, M. 1992. Short-term effects of rhizosphere microorganisms on $\mathrm{Fe}$ uptake from microbial siderophores by maize and oat. $\mathrm{Pl}$. Physiol. 100: 451-456.

Guo, X., Xiong, H., Shen, H., Qui, W., Ji, C., Zhang, Z. and Zuo, Y. 2014. Dynamics in the rhizosphere and iron-uptake gene expression in peanut induced by intercropping with maize: Role in improving iron nutrition in peanut. $\mathrm{Pl}$. Physiol. Biochem.76: 36-43.

Hasegawa, H., Azizur, M. R., Saitou, K., Kobayashi, M. and Okumura, C. 2011. Influence of chelating ligands on bioavailability and mobility of iron in plant growth media and their effect on radish growth. Environ. Exp. Bot. 71:
345-351.

Hiltner, L. 1904 U“ ber neuere erfahrungen und problem auf dem gebeit der bodenbakteriologieund unter besonderer berucksichtigung der grundungung und brache. Arbeit und Deutsche Landwirschaft Gesellschaft. 98: 59-78.

Hinsinger, P., Plassard, C., Tang, C., and Jaillard, B. 2003. Origins of rootmediated $\mathrm{pH}$ changes in the rhizosphere and their responses to environmental constraints: A review. Pl. Soil. 248: 4359.

Jacq, V. A., Prade, K. and Ottow, J. C. G. 2000. Iron sulphide accumulation in the rhizosphere of wetland rice (Oryza sativa) as the result of microbial activities. www.documentation.ird.fr/ hor/ fdi:34641.

Loper, J. E., and Buyer, J. S. 1991. Siderophores in microbial interactions on plant surfaces. Mol. Plant-Microbe Interac. 4: 5-13.

Ma, J. F., 2005, Plant root responses to three abundant soil minerals: Silicon, aluminum and iron. Crit. Rev. Plant Sci., 24: 267-281.

Morel, F. M. M. and Hering, J. G. 1993. Principles and Applications of Aquatic Chemistry: Complexation. Wiley, New York, USA.

Mori, S. and Nishizawa, N. 1987. Methionine as a dominant precursor of phytosiderophores in Graminaceae plants. Plant Cell Physiol. 28: 10811092.

Prade, K., Ottow, J. C. G. and Jacq, V.A. 1987. Excessive iron uptake (iron toxicity) by wetland rice (O. sativa $\mathrm{L}$.) on an acid sulfate soil in the Casamance/ Senegal. In: H. Dost (Editor), Selected Papers of the Dakar Symposium on Acid Sulphate Soils (January 1986). Pub 44, 150-162, I.L.R.I., Wageningen, the Netherlands, pp. 150-162. 
Robin, A., Vansuyt, G., Hinsinger, P., Meyer, J. M., Briat, J. F. and Lemanceau, P. 2008. Iron Dynamics in the Rhizosphere: Consequences for Plant Health and Nutrition. Advances in Agron. Vol. 99.

Rout, R. G., Sahoo, S. and Eskandar, H. 2011. Role of iron in plant growth and metabolism- The importance of iron $(\mathrm{Fe})$ in plant products and mechanism of its uptake by plants. J. Appl. Environ. Biol. Sci. 1(10): 448-452.

Siebner-Freibach, H., Hadar, Y., and Chen, Y.
2003. Siderophores sorbed on Camontmorillonite as an iron source for plants. Pl. Soil. 51: 115-124.

Wittenwiler, M. 2007. Mechanisms of Iron Mobilization by Siderophores Term paper in Biogeochemistry and Pollutant Dynamics, HS 07 Master Studies in Environmental Sciences ETH Zürich December 2007 Author: Guerinot, M. L., and Ying, Y., 1994, Iron: Nutritious, noxious, and not readily available. Plant Physiol. 104: 815-820.

\section{How to cite this article:}

Lokesh Patil, G.S. Yogesh, N. Hamsa and Honnappa, H.M. 2017. Dynamics of Iron in Rhizosphere. Int.J.Curr.Microbiol.App.Sci. 6(10): 3304-3312. doi: https://doi.org/10.20546/ijcmas.2017.610.387 